\title{
Rendez-vous in the oviduct: implications for superovulation and embryo transfer
}

\author{
Torben GREVE ${ }^{\mathrm{a} *}$, Henrik CALLESEN ${ }^{\mathrm{b}}$ \\ ${ }^{a}$ Royal Veterinary and Agricultural University, Department of Clinical Studies, \\ Reproduction, Dyrlægevej 68, 1870 Frederiksberg C, Denmark \\ b Danish Institute of Agricultural Sciences, Department of Animal Breeding and Genetics, \\ Reproductive Biology, 8830 Tjele, Denmark
}

(Received 15 October 2001; accepted 5 November 2001)

\begin{abstract}
The meeting between the maternal and paternal gametes is dependant upon a number of complicated processes. On the maternal side it involves maturation of the oocytes under the influence on both peripheral and follicular endocrine factors. Deviations in the normal pattern of maturation will lead to ovulation of inferior oocytes. On the paternal side the transport of spermatozoa in the female genital tract following mating is an area of great importance. The establishment of the sperm reservoir in the isthmus is dependant upon a number of factors (intracellular calcium concentrations, oligo-saccharides, change in estradiol: progesterone ratio in the afferent blood supply). Alterations of the normal micro-environment may disturb both binding, release and transport as a whole. The process of fertilization occurs in the ampullar region of the oviduct and it involves several well tuned steps: binding to the zona pellucida where the acrosome reaction takes place, penetration, fusion between the oolemma and the sperm plasma membrane, activation with the release of the cortical granules, decondensation of the sperm chromatin, pronucleus formation and finally syngamy where the two pronuclei fuses. The egg will experience the first cleavage shortly thereafter. Superovulation may disturb a number of these processes including oocyte maturation (arrest at MI) and sperm and zygote transport in the oviduct caused by the deviant endocrine environment, thus leading to a higher incidence of lack of fertilization and poor embryos quality.
\end{abstract}

oocyte maturation / capacitation / fertilization / superovulation

\footnotetext{
* Correspondence and reprints
}

E-mail: tg@kvl.dk 


\section{INTRODUCTION}

The meeting between the male and female gamete, ultimately leading to fertilization, involves a number of finely tuned processes that in principle may be adversely affected by the morphological and endocrine changes induced by the superovulatory treatment. In the following review, aspects of male and female events leading to fertilization will be discussed with special emphasis on aspects related to embryo transfer in cattle. This is by no means intended to comprise a complete review of the processes leading to fertilization, but merely highlighting the steps where the events may be adversely affected in the superovulating animal.

\section{PREPARATION}

\subsection{The oocyte}

Following the preovulatory LH-surge the oocyte and its surrounding cumulus cells, designated the cumulus oocyte complex (COC), undergoes a number of sequential changes which are essential for the oocyte to obtain fertilizing capability. The oocyte maturation has been studied in great detail in cattle by Kruip et al. [39], Callesen et al. [4] and Hyttel et al. [31, 35]. The changes include disruption of the junctions between the cumulus cell projections and the oocyte as well as breakdown of the envelope of the oocyte nucleus (ONBD) within approximately $12 \mathrm{~h}$ after the LH-peak (maximum value of LH in plasma during the LH-surge). Around $15 \mathrm{~h}$ after the LH-peak, the metaphase of the first meiotic division (MI) and rearrangement of mitochondria and vesicles are seen. Around $19 \mathrm{~h}$ after the LH-peak the first polar body is abstricted and the second metaphase (MII) appears. Around $22 \mathrm{~h}$ after the LH-peak, the cortical granules migrate from the centre of the ooplasma to solitary positions just under the oolemma, the Golgi compartment decreases and the smooth endoplasmic reticulum transforms. The COC leaves the follicle around $24 \mathrm{~h}$ in unstimulated cattle and around 24-33 h after the LH-peak in superovulated cattle.

It has, however, become increasingly clear that the normal process of oocyte maturation, both the nuclear and the cytoplasmic events described above, may be perturbed in animals treated with gonadotrophins. This includes premature maturation of the oocytes induced by the LH-contamination of the exogenous gonadotrophins $[3,4,11]$ and/or deviant peripheral endocrine profiles (premature or absent LH-surge; high progesterone concentrations at the time of heat) leading to deviant follicular steroidogenesis and abnormal oocyte maturation ultimately resulting in a decreased capacity for the oocyte to undergo normal fertilization and embryonic development $[4,31]$. Thus, a proportion of oocytes from superovulated animals will have an inherent abnormal structure that renders them inferior for subsequent normal embryonic development. The deviant follicular steroidogenic pattern, which includes abnormalities in the ratio between estradiol-17 $\beta$ and progesterone, may influence not only oocyte maturation but also the transport of oocyte and spermatozoa in the female genitalia, an aspect that will be addressed in a later section.

Besides the oocyte maturation, the cumulus investment undergoes certain essential changes including expansion and mucification. These events are important at least for the separation of the COC from the follicular wall and thus for assuring the ovulation process per se [20]. Furthermore, the COC becomes extremely sticky [12] and one may speculate whether this feature is important for the subsequent pick up by the ostium of the tuba uterina. Certainly, the mucification of in vivo produced cattle COC's is much more pronounced than in their in vitro produced counterparts (Greve, personal observation). Besides endocrine (steroids, prostaglandins) factors, an autonomic nervous regulation may be involved in the 
process of ovulation by inducing contraction of the follicular wall prior to the collapse of the preovulatory follicle [43]. Other studies have, however, shown that denervation of the ovary has no adverse effect on the ovulatory process so the effect of the nervous system is still not clear [58]. The duration of the ovulatory process is estimated to be approximately $6 \mathrm{~min}$ in the mare [55], $1.8 \mathrm{~h}$ in pigs [50] and $4-12 \mathrm{~h}$ in the superovulated cow $[3,4]$. Needless to say that the variation in the time of ovulation may affect the development stages of cattle embryos recovered on day 7 [3].

The approximate time interval from the occurrence of the pre-ovulatory LH-peak to ovulation(s) varies among animal species. For cattle it is between 24-33 h [4, 20], for pigs between 40-42 h [20] and for horses around $36 \mathrm{~h} \mathrm{[14].} \mathrm{This} \mathrm{time} \mathrm{interval} \mathrm{is} \mathrm{obvi-}$ ously important for planning the proper breeding or insemination time both in cases of spontaneous occurrence of the LH-surge and in cases where ovulation is induced by exogenous hormones.

At the time of ovulation, the ciliated epithelium of the fimbriated infundibulum sweeps the surface of the ovary to pick up the COC's [10]. Whether the cumulus cells are essential for this process is still under discussion [20] but observations from our laboratory have shown that at least in cattle, the oocytes are void of cumulus cells soon after ovulation. Following entry into the ostium, the oocyte is transported within minutes to the site of fertilization that is known to be the ampullar-isthmic region of the oviduct [20]. This transport is facilitated by the beating of the cilia and smooth muscle contractions, both of which are very active around the time of ovulation. During this passage and until the time of fertilization, the oocyte is exposed to an environment which is substantially different from the follicle and this is likely to induce certain metabolic and structural changes [20]. The transport to the ampullar-isthmic region is regulated by estradiol-17 $\beta$ and progesterone, and abnormalities in the production of these hormones - or rather their ratio which may be seen in the superovulated animal $[4,11]$ can certainly interfere with the normal oocyte transport to the site and thus the process of fertilization and the subsequent embryonic development.

A proportion of the oocytes reaching the site of fertilization in the ampullar-isthmic region is ready to be fertilized and it is important that the Rendez-vous between the oocyte and the spermatozoa takes place within a certain time interval. As reviewed by Hunter [20], the viable life span of the oocytes in the oviduct is $10-12 \mathrm{~h}$ in cattle and sheep, $8-12 \mathrm{~h}$ in the pig and about $8-10 \mathrm{~h}$ in horses. For the bitch it may be as long as 24-48 h [2]. Furthermore the age of the oocyte is inversely related to the estimated fertilization rate [25]. One could, however, argue that not all oocytes or eggs have the same viability, since a certain proportion will not be fertilized even when exposed to spermatozoa capable of fertilizing an oocyte or will undergo either embryonic or foetal death following fertilization. Extensive use of in vitro fertilization has clearly substantiated that not all oocytes of even similar appearance have the same developmental potentials. It is still unknown, however, which factor or factors contribute to the inherent quality, but the so-called "prematuration" of the oocytes seems to be important [36].

\subsection{The spermatozoa}

Following ejaculation where semen is deposited either in the anterior vagina (e.g. cattle, sheep) or in the cervix and/or uterus (pigs and horses), the spermatozoa commence a long journey towards the site of fertilization. There are numerous reviews and articles on sperm transport in the female genital tract $[16,27,28]$ and the main objective with the transport is obviously to establish a population of fertilizable or viable spermatozoa near the oocyte prior to the 
time of ovulation. This requires establishment of a functional sperm reservoir. In the section this aspect shall be given most attention.

After deposition in the vagina, a large proportion of the spermatozoa gain access to the cervical canal by their own motility and quite a large number migrates into the cervical crypts where they may remain motile for as long as 3.5 days [20, 23, 48]. These spermatozoa form some kind of a reservoir but it is questionable whether they are able to be released from the crypts and contribute to the fertilizing pool of spermatozoa since they are intimately bound to the crypt cells by the nostril part of their head (Hunter, personal communication, 1998). In addition backwards swimming movements will be required to let these spermatozoa return to the cervical canal.

It is most likely that the spermatozoa which pass through the mucus in the cervical canal are those that will establish the reservoir in the oviduct. The sperm transport through the uterus probably occurs as a combination of sperm motility and myometrial contractions [20]. In cattle the uterine tone is greatly increased during estrous whereas this is not the case in for example the mare, so different mechanisms may exist. The period in the uterus is probably important for removal of certain components from the ejaculate and may thus contribute to the capacitation process [20]. It is worth noting that a population of living spermatozoa may be present in the uterus of the bitch for as long as 11 days [8] whereas, as previously mentioned, this period in cattle and pigs is probably in the magnitude of hours.

The first spermatozoa reach the oviduct within minutes, but most studies have clearly shown that it takes from 6-8 h to establish a functional spermatozoa reservoir in the oviduct $[20,24,27]$. This reservoir is established in the utero-tubal junction (UTJ) and the lower part of the isthmus of the oviduct $[22,48,51]$. This is true for sheep [28], pigs
[19] and cattle [24] and the spermatozoa remain in this region until close to the time of ovulation. During their storage in the lower part of the isthmus and UTJ the spermatozoa bind intimately to the epithelium as visualized by electronmicroscopy [41]. The binding of at least un-capacitated bull spermatozoa to the oviduct epithelium seems to involve some kind of recognition of specific carbohydrates, lectins, on the sperm surface and oligo-saccharides on the epithelial surface $[41,52]$. The very narrow lumen of the isthmic part may in fact facilitate this binding by reducing the speed of the movement of the individual spermatozoa [52]. During the course of capacitation the previously mentioned lectins may be lost on the surface enabling the sperm to leave the epithelium and move towards the site of fertilization [52]. It is obviously important that the spermatozoa remain un-capacitated in order for them not to become hyperactivated and move towards the oocyte too early. In horses it has been shown that maintenance of a low intracellular $\mathrm{Ca}^{2++}$ concentration is important in this context [9] but other microenvironmental factors may also be important [22, 29]. The maintenance of a lower $\mathrm{Ca}^{2++}$ concentration is apparently achieved by the close contact between the sperm head and the epithelial surface [9].

The fertilizing ability of the spermatozoa is obtained after some period of contact to the epithelium and it is anticipated that the final part of the capacitation takes place during this period [48]. A completed capacitation is a prerequisite for leaving the oviduct epithelium [40], for penetration of the $\mathrm{COC}$ and for undergoing acrosome reaction (for review, see Hunter [20]). One of the very important functional changes which occurs in the spermatozoa is the so-called hyperactivation, where the sperm movements change from slow progressive to vigorous flagellar movements ([42, 53]; review: Scott [48]; personal observation, 1987). It is beyond any question that the local oviduct-ovarian endocrine environment has a decisive influence on the release and thus 
the final transport of the spermatozoa from the isthmic reservoir to the site of fertilization in the ampulla $[20,29,30]$. It was thought that the follicular fluid could enter the oviduct and thus directly affect the flux of spermatozoa but there is now convincing evidence that the effect of the follicular fluid progesterone is indirect by inducing changes in the gradients of $\mathrm{Ca}^{2++}$ which will trigger the release of the spermatozoa. Thus, the local endocrine environment probably acts through the calcium route. It goes without saying that disturbances in the follicular production of steroid hormones (e.g. progesterone and estradiol-17 $\beta$ ) as seen in association with superovulation (e.g. Callesen et al. $[4,5])$ might have an adverse effect not only on the oocyte maturation as mentioned previously but also on the sperm transport by either enhancing or delaying the release and transport of the spermatozoa towards the site of fertilization. This may ultimately lead to the formation of inferior (aged) zygotes or lack of fertilization, both of which are more frequently observed in the superovulated than unstimulated animal.

\section{THE MEETING}

The changes in the follicular fluid steroids (mainly progesterone and estrogens) which occur towards the impending ovulation is the starting signal for the spermatozoa to make the final journey towards the oocyte which is located in the distal part of the ampulla where the meeting, the process of fertilization, will take place. It is quite appropriate that fertilization has been denominated as a process since it involves several well-defined steps. The timing of sperm penetration and pronucleus formation has been examined in pigs by means of light microscopical observations $[1,18]$ and detailed ultrastructural studies of the in vivo fertilization process have been presented by Crozet [6] and Hyttel et al. [32, 35]. Valuable information on this process has also been obtained by studies of the in vitro fertilization process $[33,34]$. The cumulus cells are shed very soon after ovulation $(<10 \mathrm{~h}$, Crozet [6]), so the spermatozoa can make direct contact to the zona pellucida where the acrosome reaction occurs $[26,35,54$, $56]$. The acrosome reaction is a vesiculation that originates from fusion of the plasma membrane and the outer acrosomal membrane and results in the formation of vesicles. In the scanning electron microscope, this reaction appears as a fenestration of the membrane coats of the sperm head. Upon penetration of the zona pellucida, the spermatozoa's equatorial segment first touches and is then gradually internalised into the ooplasma. At the same time the release of the cortical granules takes place and this process will prevent entrance of more spermatozoa into the ooplasma.

The subsequent nuclear changes will lead to the formation of the paternal and maternal pronuclei and following an apposition period, these structures will fuse at around 19-20 $\mathrm{h}$ following insemination in cattle and immediately thereafter the first cleavage division takes place [32]. For details on similar processes in pigs see [18]. The fertilization process does not always occur in this normal fashion. One of the conditions particularly seen in pigs, but also in cattle, is polyspermic penetration (polyspermi). At least in cattle this condition can be directly related to deviant oocyte maturation involving abnormal distribution and release of the cortical granules as a consequence of treatment with exogenous gonadotrophins [35]. Oocytes matured in vitro, experience this condition even more frequently [34]. The biochemistry of fertilization will not be discussed in this paper, but one substance that allegedly facilitates or promotes the events leading to fertilization is the oviductal glycoproteins [57]. They may increase the capacitation and subsequent fertilization rates in cattle [38] and if purified and synthetically produced their addition to semen might be used to improve embryonic developmental rates in vitro. Other studies have 
shown that certain proteins exist in the seminal plasma of bulls with high fertility (26 kDa and $55 \mathrm{kDa}$ proteins, Killian et al. [37]).

The number of spermatozoa in the zona pellucida, denominated accessory or supernumerary spermatozoa (AS), varies with species. In pigs it reaches an average number of 106, $6 \mathrm{~h}$ after insemination [18]. In cattle the number of AS depends on a number of factors as reviewed by Saacke et al. [44-47], namely the breeding method (more AS following natural service), timing of breeding (more AS following $24 \mathrm{~h}$ versus $12 \mathrm{~h}$ and $0 \mathrm{~h}$ breeding after the first mount), embryos recovered from single versus multiple ovulating animals (more AS in single ovulating eggs) and finally the embryo quality (more AS in excellent/good embryos versus degenerate/unfertilized [47]). In ewes it has also been observed that superovulation will inhibit sperm transport [17] leading to fewer spermatozoa in all parts of the female genital tract and a lower number of AS in the zona pellucida. Again, natural breeding gave a significantly higher number of AS than artificial breeding (single ovulating 127 versus 23 or 17 per embryo).

The impairment of sperm transport and reduction in fertilization rates in the superovulated animal is a commonly accepted condition and it may be caused by the adverse endocrine environment induced by the peripheral and the follicular endocrine deviations, which by and large is a significant increase in the estrogen levels [13]. This may affect not only sperm storage, release and transport but it may also create a microenvironment which is incompatible not only with gamete transport but with proper fertilization and early development which is dependant on a very delicate balance in the oviductal secretions of small peptides $[15,21]$. The reduction in the number of AS may be explained by the subtle changes in the oviductal motility induced by the superovulatory treatment. It is, however, more difficult to give an explanation for the direct relationship between embryo quality and AS. Why are there more AS in good embryos? Because the oocytes were of higher quality, and since the oocytes compete for more fertilizing spermatozoa, then the better wins more often? It is evident though that the number of AS in embryos of good quality should be around 10-20 per embryo. It is finally interesting to note that abnormal spermatozoa do not gain zona access and thus do not constitute part of the AS population [46].

\section{DEEP UTERINE INSEMINATION}

With the emergence of sex selected semen it will be necessary to use lower doses of semen [49] because the sorting process is still rather slow. Deep intrauterine insemination may thus be an alternative to the standard cervical or uterine body deposition [26]. The advantage of this method would be an increase in a fertilizing population of spermatozoa close to the functional isthmic sperm reservoir resulting in a rise in nonreturn rates by elevating the subsequent fertilization rate. Even when not using sexed semen this aspect would be economically important. However, potential risks might be perforation of the uterine wall if the inseminator is not properly trained as well as an increase in polyspermic fertilization.

In a recent experiment conducted in our laboratory [7], we tried to use deep intrauterine insemination with reduced sperm concentration in both single ovulating and superovulated animals. The results were disappointing, since we did not obtain a satisfactory number of embryos in spite of a reasonable ovulation rate. Could this be due to an inflammatory reaction induced in the endometrium by the semen or the extender leading to impaired and even complete lack of embryonic development, maybe even total destruction? 


\section{FINAL COMMENTS: SUPEROVULATION}

From this review it has hopefully become clear that the meeting between and the final fusion of the gametes in the Fallopian tube (uterine tube or the oviduct) is a long and meticulously well tuned process which may be perturbed in several ways as a result of a superovulatory treatment. The abnormalities induced will include deviant oocyte maturation as well as abnormal peripheral and follicular endocrine events. Deviant oocyte maturation will eventually lead to formation of a gamete with reduced developmental potentials and a hostile endocrine environment. This will predispose for impaired storage and transport of the spermatozoa in all parts of the female genital tract yielding fewer or no available sperm in the vicinity of the oocyte at the time when fertilization should have taken place. The abnormal activity of the oviduct induced by the adverse endocrine conditions may also have the consequence that the transport of the zygotes and embryos are hastened leading to premature entry into the uterus. This asynchrony may well be incompatible with normal subsequent embryonic development.

Thus, there are ample risks for the whole process to run off the track, but despite all odds, superovulation and embryo recovery is a successful technique in most European countries as evidenced by AETE statistics.

\section{REFERENCES}

[1] Baker R.D., Polge C., Fertilization in swine and cattle, Can. J. Anim. Sci. 56 (1976) 105-119.

[2] Bysted B., Periovulatory events and early embryonic development in the dog. Ph.D. Thesis, Royal Veterinary and Agricultural University, Copenhagen, Denmark, 2001.

[3] Callesen H., Superovulation of cattle. Oocyte maturation, embryo quality and donor evaluation. Doctoral Thesis, Royal Veterinary and Agricultural University, Copenhagen, Denmark, 1995.

[4] Callesen H., Greve T., Hyttel P., Preovulatory endocrinology and oocyte maturation in superovulated cattle, Theriogenology 25 (1986) 71-86.
[5] Callesen H., Greve T., Hyttel P., Premature ovulations in superovulated cattle, Theriogenology 28 (1987) 155-166.

[6] Crozet N., Ultrastructural aspects of in vivo fertilization in the cow, Gamete Res. 10 (1984) 241-251.

[7] Dahlgaard P., Attempts to perform deep uterine insemination in superovulated cattle, M.S. Thesis, Royal Veterinary and Agricultural University, Copenhagen, Denmark, 2001.

[8] Doak R.L., Hall A., Dale H.E., Longevity of spermatozoa in the reproductive tract of the bitch, J. Reprod. Fertil. 13 (1967) 51-58.

[9] Dobrinski I., Smith T.T., Suarez S.S., Ball B.A., Membrane contact with oviductal epithelium modulates the intracellular calcium concentration of equine spermatozoa in vitro, Biol. Reprod. 56 (1997) 861-869.

[10] Fléchon J.E., Hunter R.H.F., Ovulation in the pig: a light and scanning electron microscope study, Proc. Soc. Study Fertil. Abstract 5 (1980) 9.

[11] Goff A.K., Greve T., Bousquet D., King W.A., Progesterone and luteinizing hormone profiles in heifers used as oocyte donors, Theriogenology 26 (1986) 577-586.

[12] Greve T., Bousquet D., King W.A., Betteridge K.J., In vitro fertilization and cleavage of in vivo matured bovine oocytes, Theriogenology 22 (1984) 151-165.

[13] Greve T., Callesen H., Hyttel P., Follicular correlates with in-vitro fertilization in cattle, J. Reprod. Fert., Suppl. 38 (1989) 117-126.

[14] Grøndahl C., Grøndahl Nielsen C., Eriksen T., Greve T., Hyttel P., In-vivo fertilisation and initial embryogenesis in the mare, Equine Vet. J., Suppl. 15 (1993) 79-83.

[15] Hansen T.H., Peptide growth factors in the bovine oviduct, Ph.D. Thesis, Royal Veterinary and Agricultural University, Copenhagen, Denmark, 2000.

[16] Hawk H.W., Transport and fate of spermatozoa after insemination of cattle, J. Dairy Sci. 70 (1987) 1487-1503.

[17] Hawk H.W., Cooper B.S., Conley H.H., Inhibition of sperm transport and fertilization in superovulating ewes, Theriogenology 28 (1987) $139-153$

[18] Hunter R.H.F., Fertilization in the pig: sequence of nuclear and cytoplasmic events, J. Reprod. Fertil. 29 (1972) 395-406.

[19] Hunter R.H.F., Pre-ovulatory arrest and periovulatory redistribution of competent spermatozoa in the isthmus of the pig oviduct, J. Reprod. Fertil. 72 (1984) 203-211.

[20] Hunter R.H.F., The Fallopian Tubes. Their role in fertility and infertility, Springer-Verlag, 1988.

[21] Hunter R.H.F., Modulation of gamete and embryonic microenvironments by oviduct glycoproteins, Mol. Reprod. Develop. 39 (1994) 176-181. 
[22] Hunter R.H.F., Sperm-epithelial interactions in the isthmus and ampulla of the Fallopian tubes and their ovarian control, in: Lauria A. et al. (Eds), Gametes: Development and Function, Serono Symposia Rome, 1998, pp. 355-367

[23] Hunter R.H.F., Nichol R., Transport of spermatozoa in the sheep oviduct: preovulatory sequestering of cells in the caudal isthmus, J. Exp. Zool. 228 (1983) 121-128.

[24] Hunter R.H.F., Wilmut I., The rate of functional sperm transport into the oviducts of mated cows, Anim. Reprod. Sci. 5 (1983) 167-173.

[25] Hunter R.H.F., Greve T., Could artificial insemination of cattle be more fruitful?, Penalties associated with ageing eggs, Reprod. Dom. Anim. 32 (1997) 137-141.

[26] Hunter R.H.F., Greve T., Deep uterine insemination of cattle: a fruitful way forward with smaller numbers of spermatozoa, Acta Vet. Scand. 39 (1998) 149-163

[27] Hunter R.H.F., Nichol R., Crabtree S.M., Transport of spermatozoa in the ewe: timing of the establishment of a functional population in the oviduct, Reprod. Nutr. Develop. 20 (1980) 1869-1875.

[28] Hunter R.H.F., Barwise L., King R., Sperm transport, storage and release in the sheep oviduct in relation to the time of ovulation, Brit. Vet. J. 138 (1982) 225-232.

[29] Hunter R.H.F., Huang W.T., Holtz W., Regional influences of the Fallopian tubes on the rate of boar sperm capacitation in surgically inseminated gilts, J. Reprod. Fertil. 114 (1998) 17-23.

[30] Hunter R.H.F., Petersen H.H., Greve T., Ovarian follicular fluid, progesterone and $\mathrm{Ca}^{2+} \mathrm{Ion}$ influences on sperm release from the Fallopian tube reservoir, Mol. Reprod. Develop. 54 (1999), 283-291.

[31] Hyttel P., Callesen H., Greve T., Ultrastructural features of preovulatory oocyte maturation in superovulated cattle, J. Reprod. Fertil. 76 (1986) 645-656.

[32] Hyttel P., Greve T., Callesen H., Ultrastructure of in-vivo fertilization in superovulated cattle, J. Reprod. Fertil. 82 (1988) 1-13.

[33] Hyttel P., Xu K.P., Greve T., Scanning electron microscopy of in vitro fertilization in cattle, Anat. Embryol. 178 (1988) 41-46.

[34] Hyttel P., Xu K.P., Greve T., Ultrastructural abnormalities of in vitro fertilization of in vitro matured bovine oocytes, Anat. Embryol. 178 (1988) 47-52.

[35] Hyttel P., Greve T., Callesen H., Ultrastructural aspects of oocyte maturation and fertilization in cattle, J. Reprod. Fertil. Suppl. 38 (1989) 35-47.

[36] Hyttel P., Fair T., Callesen H., Greve T., Oocyte growth capacitation and final maturation in cattle, Theriogenology 47 (1997) 23-32.
[37] Killian G.J., Chapman D.A., Rogowski L.A., Fertility-associated proteins in Holstein bull seminal plasma, Biol. Reprod. 49 (1993) 1202-1207.

[38] King R.S., Anderson S.H., Killian G.J., Effect of bovine oviductal estrus-associated protein on the ability of sperm to capacitate and fertilize oocytes, J. Androl. 15 (1994) 468-478.

[39] Kruip T.A.M., Cran D.G., van Beneden T.H., Dieleman S.J., Structural changes in bovine oocytes during final maturation in vivo, Gamete Res. 8 (1983) 29-47.

[40] Lefebvre R., Suarez S.S., Effect of capacitation on bull sperm binding to homologous oviductal epithelium, Biol Reprod 54 (1996) 575-582.

[41] Lefebvre R., Lo M.C., Suarez S.S., Bovine sperm binding to oviductal epithelium involves fucose recognition, Biol. Reprod. 56 (1997) 1198-1204.

[42] Nichol R., Hunter R.H.F., de Lamirande E., Gagnon C., Cooke G.M., Motility of spermatozoa in hydrosalpingeal and follicular fluid of pigs, J. Reprod. Fertil. 110 (1997), 79-86.

[43] O'Shea J.D., Phillips R.E., Contractility of ovarian follicles from sheep in vitro, J. Reprod. Fertil. 36 (1974) 457.

[44] Saacke R.G., Nadir S., Nebel R.L., Relationship of semen quality to sperm transport, fertilization, and embryo quality in ruminants, Theriogenology 41 (1994) 45-50.

[45] Saacke R.G., DeJarnette J.M., Barne J.H., Karabinus D.S., Whitman S.S., Can spermatozoa with abnormal heads gain access to the ovum in artificially inseminated super- and singleovulating cattle?, Theriogenology 50 (1998) 117-128.

[46] Saacke R.G., Dalton J., Nadir S., Bame J., Nebel R.L., Spermatozoal characteristics important to sperm transport, fertilization and early embryonic development, in: Lauria A. et al. (Eds), Gametes: Development and Function, Serono Symposia Rome, 1998, 320-335.

[47] Saacke R.G., Dalton J.C., Nadir S., Nebel R.L., Bame J.H., Relationship of seminal traits and insemination time to fertilization rate and embryo quality, Anim. Reprod. Sci. 60/61 (2000) 663-677.

[48] Scott M.A., A glimpse at sperm function in vivo: sperm transport and epithelial interaction in the female reproductive tract, Anim. Reprod. Sci. 60/61 (2000) 337-348.

[49] Seidel G.E. Jr., Allen C.H., Johnson L.A., Holland M.D., Brink Z., Welch G.R., Graham J.K., Cattell M.B., Uterine horn insemination of heifers with very low numbers of nonfrozen and sexed spermatozoa, Theriogenology 48 (1997) 1255-1264. 
[50] Soede N.M., Noordhuizen J.P.T.M., Kemp B., The duration of ovulation in pigs, studied by transrectal ultrasonography, is not related to early embryonic diversity, Theriogenology 38 (1992) 653-666.

[51] Suarez S.S., The oviductal sperm reservoir in mammals: Mechanisms of formation, Biol. Reprod. 58 (1998) 1105-1107.

[52] Suarez S.S., Carbohydrate mediated formation of the oviductal sperm reservoir in mammals, Cell Tissues Organs 168 (2001) 105-112.

[53] Suarez S.S., Katz D.F., Owen D.H., Andrew J.B., Powell R.L., Evidence for the function of hyperactivated motility in sperm, Biol. Reprod. 44 (1991) 375-381.

[54] Talbot P., Sperm penetration through oocyte investments in mammals, Am. J. Anat. 174 (1985) 331-346.
[55] Townson D.H., Ginther O.J., Duration and pattern of follicular evacuation during ovulation in the mare, Anim. Reprod. Sci. 15 (1987) 131-138.

[56] Töpfer-Petersen E., Friess A.E., Schill W.B., The acrosome reaction in boar spermatozoa, Hum. Reprod. 3 (1988) 319-326.

[57] Verhage H.G., Mavrogianis P.A., O’DayBowman M.B., Schmidt A., Arias E.B., Donnelly K.M., Boomsma R.A., Thibodeaux J.K., Fazleabas A.T., Jaffe R.C., Characteristics of an oviductal glycoprotein and its potential role in the fertilization process, Biol. Reprod. 58 (1998) 1098-1101.

[58] Wylie S.N., Roche P.J., Gibson W.R., Ovulation after sympathetic denervation of the rat ovary produced by freezing its nerve supply, J. Reprod. Fertil. 75 (1985) 369-373. 